\title{
ANÁLISE MICROBIOLÓGICA DE FÓRMULAS INFANTIS EM PÓ
}

\section{MICROBIOLOGICAL ANALYSIS OF POWDERED INFANT FORMULAS}

\author{
Kelly Cristina Strapasson', Marisa Essenfelder Borges², Edilceia Domingues do
}

\author{
Amaral Ravazzani ${ }^{3}$, Willian Barbosa Sales ${ }^{4}$, Cristina Peitz Lima ${ }^{5^{*}}$
}

1 - Nutricionista formada pelo Centro Universitário Autônomo do Brasil, Unibrasil.

2 - Bióloga, docente da Escola de Saúde do Centro Universitário Autônomo do Brasil, Unibrasil.

3 - Nutricionista, docente do curso de Nutrição do Centro Universitário Autônomo do Brasil, Unibrasil.

4 - Biólogo, docente do Centro Universitário Internacional Uninter.

5 - Farmacêutica, docente da Escola de Saúde do Centro Universitário Autônomo do Brasil, Unibrasil.

RESUMO: A fórmula infantil é a única ou a predominante fonte alimentar para muitos lactentes. Sendo assim, analisar as fórmulas infantis em pó é de extrema importância para avaliar as condições higiênico sanitárias do produto. Objetivo: avaliar a presença de microrganismos patogênicos em fórmulas infantis em pó, comercializadas em CuritibaParaná e relacionar os resultados com a RDC №12/2001 da Agência Nacional de vigilância Sanitária. Foi realizado um estudo quantitativo com 6 amostras de diferentes especificidades e 3 marcas disponíveis no mercado, no qual foram realizadas análises microbiológicas avaliando a presença de salmonella sp., Staphylococus aureus e Grupo Coliforme em fórmulas infantis em pó pelo método Petrifilm® (3M Company). Resultado: Após a análise, observou-se que não houve crescimento de microrganismos nas amostras, estando de acordo com os padrões microbiológicos estabelecidos pela Resolução RDC №12/2001 da Agência Nacional de Vigilância Sanitária. As fórmulas infantis em pó analisadas atenderam o padrão de qualidade e não confirmou as evidencia de contaminação no processamento, o que representa que as boas condições higiênicas sanitárias do produto resultaram em uma fórmula microbiologicamente segura para as crianças. Contudo, para que não ocorra a contaminação com microrganismos patogênicos na reconstituição da fórmula, as boas práticas de manipulação devem ser seguidas tanto em âmbito hospitalar como residencial.

PALAVRAS-CHAVE: microbiologia de alimentos; Fórmula infantil; Salmonella; Staphylococcus aureus; Grupo Coliforme.

Abstract: The infant formula is the only or predominant source for many infants. Thus, analyzing the infant formulas powder is extremely important to evaluate the sanitary hygiene conditions of the product. Objective: To evaluate the presence of pathogenic microorganisms in powdered infant formulas commercialized in Curitiba-Paraná and relate the results with RDC N ${ }^{\circ} 12 / 2001$ of the National Health Surveillance Agency. A quantitative study was carried out with 6 samples of different specificities and 3 brands available in the market, in which microbiological analyses were performed evaluating the presence of Salmonella sp., Staphylococus aureus and Coliform group in formulas The Petrifilm ${ }^{\circledR}$ method (3M Company). Results: After the analysis, it was observed that there was no growth of microorganisms in the samples, being in accordance with the microbiological standards established by resolution RDC N ${ }^{\circ} 12 / 2001$ of the National Health Surveillance Agency. The powdered infant formulas analyzed met the quality standard and did not confirm the evidence of contamination in the processing, which represents that the good sanitary hygiene conditions of the product resulted in a microbiological safe formula for the children. 
However, in order to not occur contamination with pathogenic microorganisms in the reconstitution of the formula, good manipulation practices should be followed both in the hospital and residential areas.

KEYWORDS: food microbiology; Infant formula; Salmonella; Staphylococcus aureus; Coliform Group.

\section{INTRODUÇÃO}

Fórmula infantil é um produto destinado a satisfazer as carências nutricionais dos recém-nascidos e crianças impedidas de serem amamentadas e devem seguir as recomendações do Codex Alimentarius, que é uma coleção de padrões alimentares adotados internacionalmente que estabelece diretrizes e códigos que contribuem para a segurança e qualidade dos produtos (WHO, 2011).

As fórmulas devem apresentar conteúdos específicos de acordo com as necessidades dos lactentes, atendendo possíveis carências nutricionais que provém de mudanças fisiológicas, doenças transitórias ou permanentes e/ou para a diminuição de alergias em bebês e recém-nascidos propensos (BRASIL, 2011b). Apesar da inviabilidade de produzir um produto idêntico ao leite materno, todos os esforços da industria são aplicados no intuito de que o produto atenda às recomendações do Codex Alimentarius e proporcionem crescimento e o desenvolvimento adequado da criança. São produzidas a partir do leite de vaca e/ou de soja, acrescidas de ingredientes atendendo as recomendações estabelecidas em legislação própria (MARTIN; LING; BLACKBUR, 2016; WEFFORT, 2012).

Considerando os padrões microbiológicos, as fórmulas precisam estar adequadas à RDC nำ12 de 2001, a qual estabelece o perfil aceitável para fórmulas infantis que serão consumidas por bebês até um ano de idade, com ou sem adição de líquidos (BRASIL, 2001a). É imprescindível que alimentos direcionados a crianças e bebês menores de um ano sejam nutricionalmente adequados e microbiologicamente seguros. Infeções que ocorrem ao longo do primeiro ano de vida estão relacionadas a elevação do índice de morbimortalidade. Os principais riscos microbiológicos relacionados as fórmulas infantis em pó, podem ocorrer na indústria, no processo de adição dos ingredientes e na reconstituição das fórmulas (SIMO et al, 2010.; ROSSI; KABUKI; KUAYE, 2010.; FREITAS et al., 2011).

Alimentos secos como as fórmulas infantis não são produtos esterilizados, e pode ocorrer contaminação intrínseca com agentes patogênicos. A Salmonella e Cronobacter sakazakii são as principais bactérias envolvidas em intoxicações alimentares e infeções graves em crianças, sendo um problema de saúde pública (YANG et al., 2014). A fórmula 
infantil em pó tem sido relacionada com bactérias que causam enterite necrosante, meningite, meningoencefalite, septicemia, entre outras doenças, acometendo principalmente bebês e recém-nascidos (KENT et al., 2015.; XU, X et al. 2010.; ROSSI; KABUKI; KUAYE,2010).

Estudos realizados na França e Espanha encontraram a presença de Salmonella e Cronobacter sakazakii em fórmulas infantis em pó. No Brasil há casos de infecções relacionados com fórmula infantil em pó contaminada e o microrganismo que causou a patogenicidade foi a Cronobacter sakazakii (BRANDÃO; UMEDA; FILIPPIS, 2018.; LINHARES, 2012.; SIMO et al., 2010). Portanto, analisar as fórmulas infantis em pó, se torna um procedimento importante para avaliar o controle de qualidade e as condições higiênico sanitárias do produto. O objetivo do presente estudo foi analisar a presença de Salmonella sp., Staphylococus aureus e Grupo Coliforme nas fórmulas infantis em pó.

\section{MATERIAL E MÉTODO}

Para realização do presente estudo foram utilizadas seis (06) latas de fórmulas infantis de partida, Todas as amostras utilizadas encontravam-se dentro do prazo de validade. Foram excluídas as latas sem o lacre protetor, amassadas e as que continham qualquer tipo de avaria na embalagem ou no rótulo. As amostras foram adquiridas em estabelecimentos comerciais (supermercado, farmácias) localizados na Cidade de CuritibaParaná. Após a aquisição das latas de fórmula infantil em pó, estas foram direcionadas para o laboratório de microbiologia do Centro Universitário Autônomo do Brasil - UniBrasil, para execução das análises microbiológicas.

As análises microbiológicas foram realizadas pelo método Petrifilm® (3M Company) - método oficial da Association of Official Analytical Chemists (AOAC). O método Petrifilm® realiza uma modificação na coloração para a contagem de unidades formadoras de colônia (UFC) em placas. Foram colocadas as bactérias nas placas para haver a multiplicação, para assim testar o lote das placas e verificar se estavam funcionando.

No laboratório, foram codificados como amostra A, B, C, D, E e F. As latas e os utensílios foram higienizados com etanol $70 \%$ para assepsia. Foram pesadas 25 gramas de cada amostra, adicionadas a $225 \mathrm{ml}$ de água peptona estéril e homogeneizadas por 1 minuto. Em seguida, foram realizadas três diluições seriadas $\left(10^{-1}, 10^{-2}, 10^{-3}\right)$ compostas por $9 \mathrm{ml}$ de água peptonada e $1 \mathrm{ml}$ da amostra. Com o auxílio de uma pipeta, foi inoculado $1 \mathrm{ml}$ da terceira diluição no filme inferior da placa Petrifilm®, e recoberto com o filme 
superior. Após a solidificação do gel, as placas foram incubadas de $35^{\circ} \mathrm{C}$ a $37^{\circ} \mathrm{C}$ por 48 horas para o desenvolvimento das colônias. Todo o material utilizado para o processamento das amostras estava estéril e toda a operação foi realizada próxima a um bico de Bunsen com a chama a meia altura em uma câmara de fluxo laminar (SALES; CAVEIÃO; VALENTIN; CASTRO, 2016).

\section{RESULTADOS E DISCUSSÃO}

Após análise das placas observou-se que não houve crescimento de microrganismos, estando de acordo com os padrões microbiológicos estabelecidos pela Resolução RDC №12/2001 da Agência Nacional de vigilância Sanitária, no qual os limites quantitativos máximos aceitáveis nas fórmulas para bebês até 1 ano, são de ausência de unidade formadora de colônia (UFC) de Coliforme a $45^{\circ} \mathrm{C} / \mathrm{g}$, Estafiloccocus coagulase positiva ( $\mathrm{g} / \mathrm{ml}$ ) e Salmonella sp 25g/ml (BRASIL, 2001a).

O resultado do presente estudo provavelmente se dá ao fato das indústrias implementarem os critérios estabelecidos na RDC №275/2002 da Agência Nacional de vigilância Sanitária, que dispõe sobre o Regulamento Técnico de Procedimentos Operacionais Padronizados - POP's e a Lista de Verificação das Boas Práticas de Fabricação aplicados aos Estabelecimentos Produtores/Industrializadores de Alimentos. Os POP's, são um instrumento que apresenta instruções, que devem ser descritos de forma objetiva, a fim de que sejam implementados e executados nas rotinas da produção, armazenamento e transporte dos alimentos. Temas com limpeza, desinfecção, higienização, antissepsias, controle integrado de pragas, recolhimentos de alimentos e descarte de resíduos, são parte integrante do instrumento. Todos esses procedimentos têm como finalidade reduzir os riscos físicos químicos e biológicos dos alimentos e a Lista de Verificação das Boas Práticas de Fabricação serve para examinar se os procedimentos de manutenção e higienização dos utensílios, equipamentos, das instalações, controle de água que abastece o local, entre outros, estão sendo realizadas corretamente pelos manipuladores, para que assim haja a garantia e qualidade do produto final (BRASIL, 2002b).

As fórmulas infantis também são submetidas à um processo de esterilização que envolve a alta temperatura, o que parece ser efetivo para eliminar a presença de possíveis microrganismos. Vale ressaltar que nas fases subsequentes, onde são adicionados ingredientes, podem ocorrer contaminações microbiológicas, assim a torre de secagem do 
leite e equipamentos que envolvem o processo de fabricação da fórmula podem ser uma importante fonte de contaminação caso não haja a correta higienização. Desta forma, a intensa efetividade da aplicação dos procedimentos propostos nas resoluções da ANVISA depende da correta execução dos conceitos que a envolvem.

Diretriz sobre a determinação do prazo de validade de alimentos, publicada pela Agência Nacional de Vigilância Sanitária, propõe que alimentos comercializados sob a forma seca, como as fórmulas infantis em pó, devem apresentar o nível mais baixo de umidade para não ocorrer crescimento microbiano (Agência Nacional de Vigilância Sanitária, 2018). Industrialmente, nas embalagens que contém as fórmulas infantis, a atmosfera é modificada, $\mathrm{o}$ ar do interior da lata pode ser substituído por oxigênio $\left(\mathrm{O}_{2}\right)$, dióxido de carbono $\left(\mathrm{CO}_{2}\right)$ ou nitrogênio $\left(\mathrm{N}_{2}\right)$. Esse é um processo realizado para aumentar a conservação do produto, e serve como bacteriostático aos microrganismos. O gás utilizado depende do produto e dos microrganismos associados (MANTILLA; VITAL; FRANCO; BORGES, 2017).

Por outro lado, a Organização das Nações Unidas para a Agricultura e Alimentação (FAO) e a Organização Mundial da Saúde (OMS), tem estudado e apontado a Cronobacter e Salmonella entérica, como microrganismos patogênicos que estão nitidamente envolvidos a doenças em recém-nascidos e crianças devido à presença em fórmulas infantis em pó (MORLAY et al, 2016). Infecções causadas por Salmonella, devido à ingestão de fórmulas contaminadas, estão associadas a recém-nascidos saudáveis, no entanto bebês imunocomprometidos estão mais suscetíveis a doenças graves. Fórmulas infantis em pó podem conter bactérias patogênicas que causam infecções como meningite, bacteremia e enterocolite necrotizante, fortalecendo o importante cuidado no momento da reconstituição da fórmula oferecida aos bebês (FORSYTHE, 2013.; LOSIO et al., 2018).

Salienta-se que o gênero Cronobacter spp. tem sido diretamente relacionado com infecções agressivas em pessoas imunocomprometidas, principalmente em recémnascidos e idosos (HENRY; FOULADKHAH, 2019.; FLORES, 2018). A C. sakazakii contém estirpes que podem entrar nas células intestinais, multiplicar-se em macrófago e invadir 0 sangue e cérebro. A dose suficiente para surgir a infecção não foi determinada, contudo há relatos de que foram achados microrganismos em fórmulas infantis em pó de $(<1 \mathrm{ufc} / \mathrm{g})$, sendo assim, estando em temperatura favorável, haverá multiplicação bacteriana (SANTO, 2013; FORSYTHE, 2013).

Surtos são uma preocupação e já foram citados em países considerados desenvolvidos, como os Estados Unidos, onde ocorreu um surto em bebês, no qual a 
bactéria envolvida foi a Salmonella, e supostamente a contaminação ocorreu nos secadores de pulverização. Outro país que apresentou um grande surto de infecção por Salmonella foi a Austrália, onde em análise de amostras, foram isoladas bactérias em 7 tipos de leite em pó, e determinado que a contaminação também ocorreu nos secadores de spray dryer (Ângulo et al, 2008).

Através de estudos realizados em fórmulas infantis em pó na Turquia, 7 amostras analisadas continham Cronobater sakazakii (DEMIRCI; TEKINER; ÇACMAK; ÖSPINAR, 2018). Após a ocorrência de um caso de meningite em uma unidade de cuidados intensivos neonatal, foi isolado Cronobater sakazakii de uma fórmula aberta e duas fechadas, todas do mesmo lote. Nas amostras das fórmulas infantis em pó, nas amostras do sangue e das fezes do recém-nascido, constataram a mesma bactéria e resistência a antibióticos (SIMO, et al. 2010).

Após intercorrência de um surto em 11 regiões da França, envolvendo 31 casos confirmados com idade média de 2 a 28 meses, um total de 13 bebês tiveram diarreia com sangue, causado por S. Poona. Após estudos, concluíram que a fonte de contaminação foi na indústria, na torre de secagem (JONES et al, 2019). No Brasil, em Minas Gerais, Piauí, Rio de Janeiro e São Paulo foram encontrados casos de infecções em crianças, neonatos, no qual o microrganismo relacionado com a contaminação nas fórmulas infantis em pó foi a Cronobacter sakazakii. Este surto levou um recém-nascido a óbito (BRANDÃO; UMEDA; FILIPPIS, 2018).

É importante destacar que, apesar das fórmulas em pó avaliadas não apresentarem contaminações no presente estudo, o momento da reconstituição, ou seja, o preparo da fórmula para ser consumida pela criança, pode ser um momento de risco para a contaminação por microrganismos patogênicos, seja por meio do manipulador, poeira do ar, dos equipamentos, utensílios utilizados na adição do ingrediente, no armazenamento e/ou mesmo no momento de sua administração à criança. Desta forma, é importante haver controle higiênico sanitário em todas as etapas de preparação da fórmula (PEREIRA et al., 2013; ROSSI; KABUKI; KUANE, 2010). A alimentação da criança, principalmente na fase inicial da vida é de fundamental importância. Evitar o contato com bactérias que possam causar dano a saúde é parte integrante do cuidado. A utilização de procedimentos, tais como, utilização de água fervida, higienização de utensílios, mamadeiras e arruelas juntamente com a utilização de fórmulas adequadas, permite a garantia de uma alimentação segura e adequada àquelas crianças que, por motivos adversos, não podem 
ser amamentadas por suas mães e precisam utilizar as fórmulas infantis (OLIVEIRA, MORENO e SILIANO, 2017).

Os custos elevados para realização de análises microbiológicas pode ser impedimento para que mais análises sejam realizadas em todas as etapas do preparo de alimentos, desta forma, a aplicação de medidas que diminuam as possibilidades de contaminação são necessárias, em ambientes hospitalares e principalmente no âmbito do domicilio. Assim, o profissional de saúde, em especial o nutricionista, tem um papel importante na disseminação de informações sobre os cuidados que devem ser implementados durante o preparo das fórmulas infantis.

Dessa forma, para garantir a segurança do produto final oferecido à criança, faz-se necessário cuidados provindos do manipulador de alimentos, como a higienização correta dos utensílios, das mãos, a utilização de água potável, a aquisição de fornecedores confiáveis e a cautela com o tempo e temperatura do produto. Para tanto, é imprescindível treinamento de boas práticas de manipulação tanto para a mãe que prepara em âmbito residencial, como para manipuladores a nível hospitalar, para assim obterem a conscientização dos devidos cuidados, para que não ocorram as Doenças transmitidas por alimentos.

\section{CONCLUSÃo}

Comparando com os padrões microbiológicos estabelecidos pela Resolução RDC №12/2001 da Agência Nacional de vigilância Sanitária, as fórmulas infantis em pó avaliadas encontram-se dentro dos padrões microbiológico. Isso demonstra que as boas condições higiênico sanitárias do produto resultaram em uma fórmula microbiológicamente segura para as crianças. Entretanto, para obter um produto final seguro, cuidados devem ser tomados em todo o processo de manuseio: utensílios e equipamentos devem estar em boas condições higiênico sanitárias e deve-se observar o tempo e a temperatura no momento do preparo final da fórmula. Tudo isso deve ser considerado para, assim, garantir um alimento seguro para ser administrado as crianças.

\section{REFERÊNCIA}

Agência Nacional de Vigilância Sanitária. Guia para determinação de prazos de validade de alimentos. 2018. Disponível: http://portal.anvisa.gov.br/documents/10181/5056443/Guia 
+16_2018+Prazo+de.pdf/e40032da-ea48-42ff-ba8c-a9f6fc7af7af>>. Acesso em agosto de 2019.

BRANDÃO, M, L, L.; UMEDA, N, S.; FILIPPIS, I. Cronobacter spp.: infections, ocurrence and food regulations - a review in Brasil. Journal Food Tehnology, v 21, e2017074, 2018.

BRASIL. Agência Nacional De Vigilância Sanitária. Resolução RDC n`12 de janeiro de 2001. Dispõe de critérios e padrões microbiológicos para alimentos, indispensáveis para a avaliação das Boas Práticas de Produção de Alimentos e Prestação de Serviços. Diário Oficial da República Federativa Do Brasil. Poder Executivo, Brasília. DF, n. 3029, de 16 de abril de 1999, em reunião realizada em 20 de dezembro de 2000.

BRASIL. Agência Nacional De Vigilância Sanitária. Resolução RDC n²75 de Dispõe sobre o Regulamento Técnico de Procedimentos Operacionais Padronizados aplicados aos Estabelecimentos Produtores/Industrializadores de Alimentos e a Lista de Verificação das Boas Práticas de Fabricação em Estabelecimentos Produtores/Industrializadores de Alimentos. Diretoria Colegiada da Agência Nacional de Vigilância Sanitária. Regimento Interno aprovado pela Portaria no 593 , de 25 de agosto de 2000, republicada no DOU de 22 de dezembro de 2000, em reunião realizada em 16 de outubro de 2002.

DEMIRCI, Ü.; TEKINER, I, I; ÇAKMAK, B.; ÖZPINAR, H. Ocorrência e caracterização molecular de diferentes genes associados à virulência de isolados de Cronobacter sakazakii de alguns alimentos e amostras de poeira. Ciências Rural v.48,n. 8, e20180127, 2018.

FLORES, J, P.; LEAL, F, C.; CONTRERAS, A.; RIFFO, N, V.; RODRIGUES, A.; AGUIRRE, J. Cronobacter sakazakii and microbiological parameters in milk formulas associated with a food alert Chile. Frontiers in Microbiology. v. 9, 2018. https://doi.org/10.3389/fmicb.2018.01708.

FORSYTHE, S., J. Microbiologia da segurança dos alimentos. $2^{\circ}$ edição. São Paulo: Editora Artmed, 2013. 
FREITAS, G, L.; RISTORI, A, C.; JAKABI, M.; PAULA, A, M, R.; ROWLANDS, E, G. Ocorrência de Cronobacter spp. (Enterobacter sakazakii) em alimentos infantis adquiridos em um hospital público. Instituto Adolfo Lutz. v. 70, n. 4, p. 548-553, 2011.

HENRY, M.; FOULADKHAH, A. Outbreak History, Biofilm Formation, and Preventive Measures for Control of Cronobacter sakazakii in Infant Formula and Infant Care Settings. Microorganisms. v. 7, n. 3, 77, 2019. https://doi.org/10.3390/microorganisms7030077

JONES, G.; GANDARA, M, P.; HERRERA-LEON, L.; HERRERA-LEON, S.; MARTINEZ, C, V.; HUREAUX-ROY, R.; ABDALLAH, Y.; NISAVANH, A.; FABRE, L.; RENAUDAT, C, M, J.; MATTHEUS, W.; HUARD, C.; LE BORGNE, C.; VALK, H.; WEILL, F, C.; SILVANATHALIE, J. Outbreak of Salmonella entérica sorotipe poona in infants liked to persistent contamination at a manufacturing facility for infant formulas, France, from august 2018 to february 2019. Revista Eurosurveillance. v.24, n. 13, p. 548 a 553, 2019. https:// doi.org/10.2807/1560- 7917.ES.2019.24.13.1900161.

KENT, R. M.; FITZGERALD, G. F.; HILL, C.; STANTON, C.; ROSS, R. P. New approaches to improving the intrinsic microbiological safety of infant formula powder. Magazine Nutrients. v. 7, n. 2, p.1217 a 1244, 2015.

LINHARES, Ingrid Werneck. Avaliações das condições higiênico sanitárias no preparo de fórmulas infantis em lactário hospitalar. 2012. Dissertação (Ciências de alimentos) Universidade Federal de Minas Gerais, 2012.

LOSIO, M, N.; PAVON, I, E, F, G.; A, C.; DAMINELLI, P.; DALZINI, E.; VARISCO, G.; CINOTTI, S. Preparation of Powdered Infant Formula: Could Product's Safety Be Improved? Journal Pediatr Gastroenterol Nutr. v. 67, n. 4. p. 543-546, 2018.

MAURíCIO, R, A.; MARTA, B, B, F.; PETRONI, T, F.; BRONHARO, T, M.; MICHELIN, A, F. Qualidade microbiológica de formulações lácteas infantis manipuladas em hospital. Journal of the Health sciences Institute. V.35, n. 2, p.112-116, 2017. 
MANTILLA, S, P, S.; VITAL H.; BORGES, S.; FRANCO, R.; Atmosfera modificada na conservação os alimentos. Rev. Acad. Ciências Agrária Ambiental. v. 8, n. 4, p. 437-448, 2010.

MARTIN, C., R.; LING, Pei-ra.; BLACKBURN, G., L. Review of infant feeding: main characteristics of breast milk and infant formula. Magazine Nutrients. v. 8, n. 5, 2016. https://dx.doi.org/ $10.3390 \% 2 F n u 8050279$.

MORLAY, A. PIAT, F. MERCEY, T. ROUPIOZ, Y. Immunological detection of Cronobacter and Salmonella in powdered infant formulas by assay without plasmid label. Letters in Applied Microbiology. v. 62, n.6, p.459-65, 2016. https://doi.org/10.1111/lam.1257.

OLIVEIRA, J. E. M.; MORENO, G. O.; SILIANO, P. R. Identificação de bactérias presentes em bicos de mamadeiras e em copos infantis. Revista Higei@ UNIMES. v. 1, n. 2, 2017.

PAIVA, E, S.; AVELAR, K, E, S.; FILHO, J, T, S.; MELLO, S, R, P.; CARDOSO, F, T. Qualidade microbiológica da água utilizada na reconstituição de alimentos infantis utilizados em unidades hospitalares pediátricas da rede privada na cidade do Rio de Janeiro. Rev Semioses. v. 10, n. 1, p, 79-82, 2016.

PEREIRA, A.; COSTA, B, M, S.; NASSER, E, M.; SILVA, J, F.; PEIXOTO, J, C, M, SILVA.; JANDRE, M, C. Avaliação microbiológica de fórmulas infantis manipuladas em Unidades Centralizada de produção. Segurança Alimentar e Nutricional. v. 20, n. 2, p. 260-274, 2013.

ROSSI, P.; KABUKI D, Y.; KUAYE, A, Y. Microbiological evaluation of the preparation of infant formula in hospital lactario. Rev Inst. Adolfo Lutz. v. 69, n. 4, p. 503-508, 2010.

SALES, W, B.; CAVEIÃO, C.; V, D; CASTRO, L. Análise microbiológica em ricotas frescal no município de Curitiba - Pr. Revista De Biotecnologia \& Ciência. v. 5, n.1, p.16-24, 2017.

SANTOS, R, F, S.; SILVA, N.; JUNQUEIRA, V, A.; KAJSIK, M.; FORSYTHE, S. Screening for cronobacter species in powdered and reconstituted infant formulas and from equipment 
used in formula preparation in maternity hospitals. Annais of Nutrition \& Metabolism. v. 63, p.62- 68, 2013. https://doi.org/ 10.1159/000353137

SHINOHARA, N, K, S.; BARROS, B, V.; JIMENE, C, S, M.; MACHADO. Salmonella spp., importante agente patogênico veiculado em alimentos. Ciências saúde coletiva. v. 13, n. 5. p. 1675-1683, 2008. https://doi.org/101590/s1413-81232008000500031. Set/out de 2008.

SIMO, M.; SABATE, S.; OSANZ, A, C.; BARTOLOME, R.; FERRER, M,D Investigation of a neonatal case by Enterobacter sakazakii associated with a powdered infant formula. Magazin Elsevier Doima. v. 28, n. 10, p.713-715, 2010. https://doi 713-115.

WEFFORT, V, R, S. Avanços nutricionais em fórmulas infantis. Revista Pediatria Moderna. v. 48, n 4, p. 115 - 120, 2012.

WHO. Comisión del Codex Alimentarius. Manual de procedimento. 20ํedición. Organización Mundial de La Salud y Organización de lãs Naciones Unidas para la Agricultura y laAlimentación. Roma; 2011.

WORLD HEALT ORGANIZATION. Protecting, promoting and supporting breastfeeding in facilities providing maternity and newborn services. 2017. Disponível em: <http://apps.who.int/iris/bitstream/handle/10665/259386/9789241550086-eng.pdf; Jsessionid =6B11F5A0EB9E4660874D60E1A40C764E?sequence=1 >> Acesso em 24 out 2018.

XU, X.; WU, Q.; ZHANG, J.; YE, Y.; YANG, X.; DONG, $\quad$ X. Occurrence and characterization of cronobacter spp. In the formula of Chinese retail market powder. Foodborne Pathog Dis. V. 11, n.4, p. 637-644. 2014.

YANG, B.; ZHAO, H.; UI, S.; WANG, Y.; XIA, X.; XI, M.; WANG, X.; MENG, J.; GE, W. Prevalence and characterization of enteric salmonella. American Dairy Science Association. v.97, n.11, p. 6754 a 6759, 2014. http://dx.doi.org/ 10,3168 / jds.2014-8292.

Autor para correspondência:

Cristina Peitz Lima

Email: cristinapeitz@hotmail.com

Escola de Saúde do Centro Universitário Autônomo do Brasil, Unibrasil, Recebido:

05/02/2021 Aceito: 27/03/2021 